\title{
SAR assessment on three layered spherical human head model irradiated by mobile phone antenna
}

Balamurugan Rajagopal and Lalithambika Rajasekaran ${ }^{*}$

\author{
* Correspondence: \\ srlalithambika@gmail.com \\ Anna University Regional Centre, \\ Coimbatore 641047 TN, India
}

\begin{abstract}
With the increasing application of wireless communication devices, mobile phone handsets are used by peoples of various age groups. This paper make an effort to asses the mobile phone radiation exposure effect on 4 years old, 8 years old children and an adult head model. Here, human head is modeled as a three layered sphere composed of skin, skull and brain. Hand held device model (with and without resistive sheet) having dipole antenna enclosed by plastic cover is used for human interaction. The software simulation performed by General Electro Magnetic Simulator, based on Finite Difference Time Domain technique yields Specific Absorption Rate and 3D-thermal distribution on spherical human head. Comparison of $1 \mathrm{~g}$ SAR, $10 \mathrm{~g}$ SAR values for adult and children head show that, children head absorbs more power than adult. Further, the application of resistive sheet on handset shows effective decrement in coupled power.
\end{abstract}

Keywords: Finite Difference Time Domain (FDTD); Specific Absorption Rate (SAR); Thermal effect; Electro Magnetic (EM) radiation

\section{Introduction}

With the rapid increase in technology, the world without communication is unimaginable. So, mobile phone handset devices act like another hand to human society. Every product has its own advantages as well as disadvantages. However, we never thought of biological ill effects due to mobile phones a wireless communication device used by various age groups [1]. The abundant usage of handsets has kindled some interest in few scientist and researchers regarding the ill effects due to Electro Magnetic radiation emitted by mobile phone antenna. Some research studies shows that, while placing mobile phone nearer to head, the emitted EM radiation gets coupled to human head tissues, which might alter the basic biological function of cells. Even, we can sense the temperature increment in outer case of handset as well as ear, where handsets are pressed while talking for longer hours.

The temperature increment in human tissue is due to power coupled and it may vary with interacting environment. However, the sensed heat gets eventually decreased to equilibrium due to blood circulation. The consequences of excessive heating in the body vary from temporary disturbances in cell functions to permanent destruction of tissues. Areas with less efficient cooling by the circulation, e.g. the lens of the eye, brain cells are more 
susceptible to electromagnetic radiation. Since, the usage of mobile phones is inevitable in this modern technological world, and the radiation exposure from mobile phone is non uniform, limits can be précised in terms of Specific Absorption Rate (SAR) with an averaging mass of $1 \mathrm{~g}$ and $10 \mathrm{~g}$ of tissue in the shape of cube. Further, heat induced in tissues signifies the well known adverse health effect at microwave frequencies [2,3]. The analysis of power absorbed by the human head and the antenna performance are necessary for the compliance testing of mobile phones performance. This coupled field can be efficiently calculated by numerical method based on finite difference time domain technique [4].

This paper endeavor to assess the health hazards, particularly the power absorbed by tissues and thermal effects due to exploitation of mobile phones. Further, a simple and comprehend method of SAR decrement due to usage of resistive sheet on user-front side of handset case is also introduced and performance is analyzed. The work includes evaluation of specific absorption rate for children and adult with same electromagnetic environment. Results might enlighten the mobile phone users regarding radiation exposure effect from mobile phones and, ultimately results in the minimization of an individual's risks.

Section Model development includes development of mobile phone antenna model, human head model and hand held device model. Section Measurement of power absorbed gives description about measurement of SAR and heat induced when mobile phone is in proximity with the human head model. Section Numerical results and discussions comprises of numerical results and discussions. Finally, section Conclusion covers the conclusion of the work.

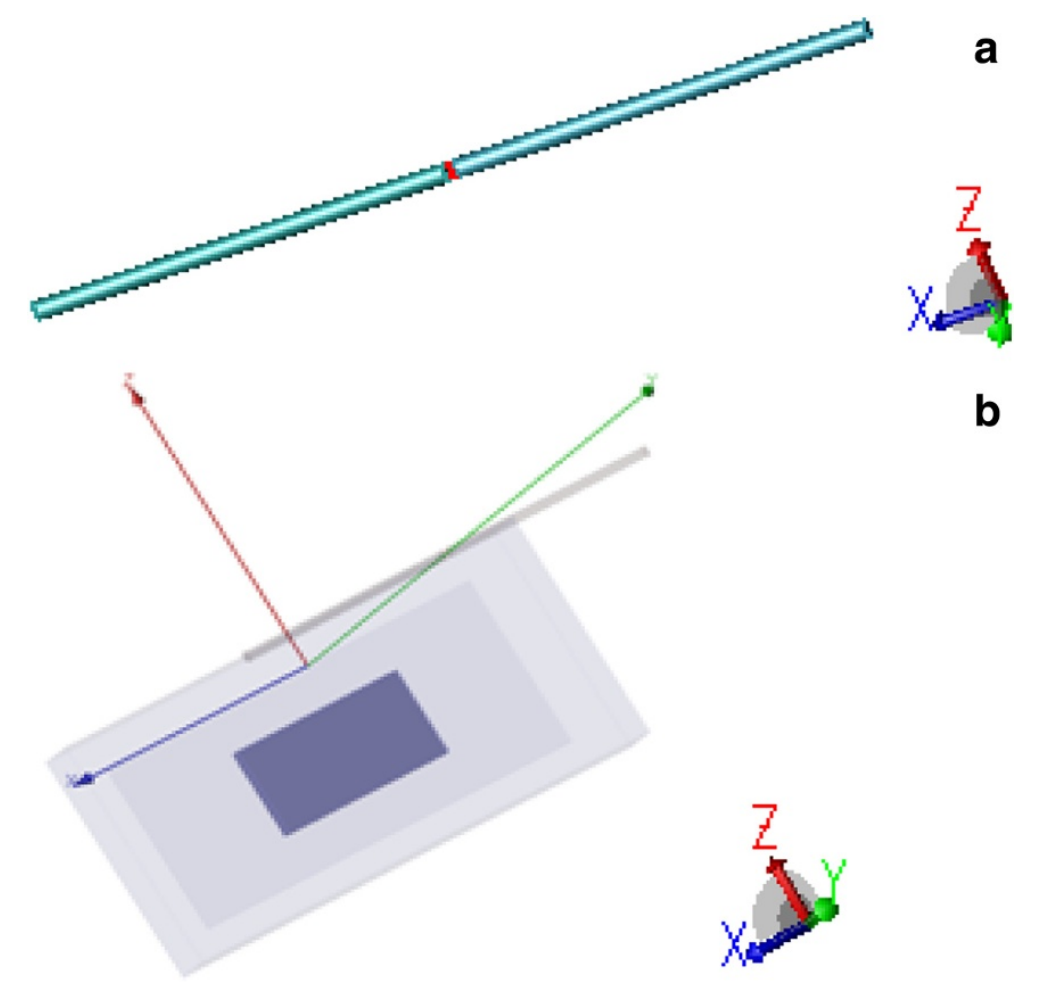

Figure 1 Half- Wave length dipole antenna is designed for $900 \mathrm{MHz}$ frequency and is embedded in Mobile phone casing for Near field interaction analysis. a Dipole Antenna [simulated dipole antenna with excitaion feed at the centre]. b Mobile Phone Model [mobile handset model with dipole antenna embedded]. 


\section{Model development}

Antenna model

In this work, $(\lambda / 2)$ dipole antenna (shown in Figure 1) with single excitation port is placed in free space [3]. The length of the half wavelength dipole is $147 \mathrm{~mm}$ for the operating frequency range of $0.9-1.5 \mathrm{GHz}$. The feed gap size is $1.8 \mathrm{~mm}$, hence the length

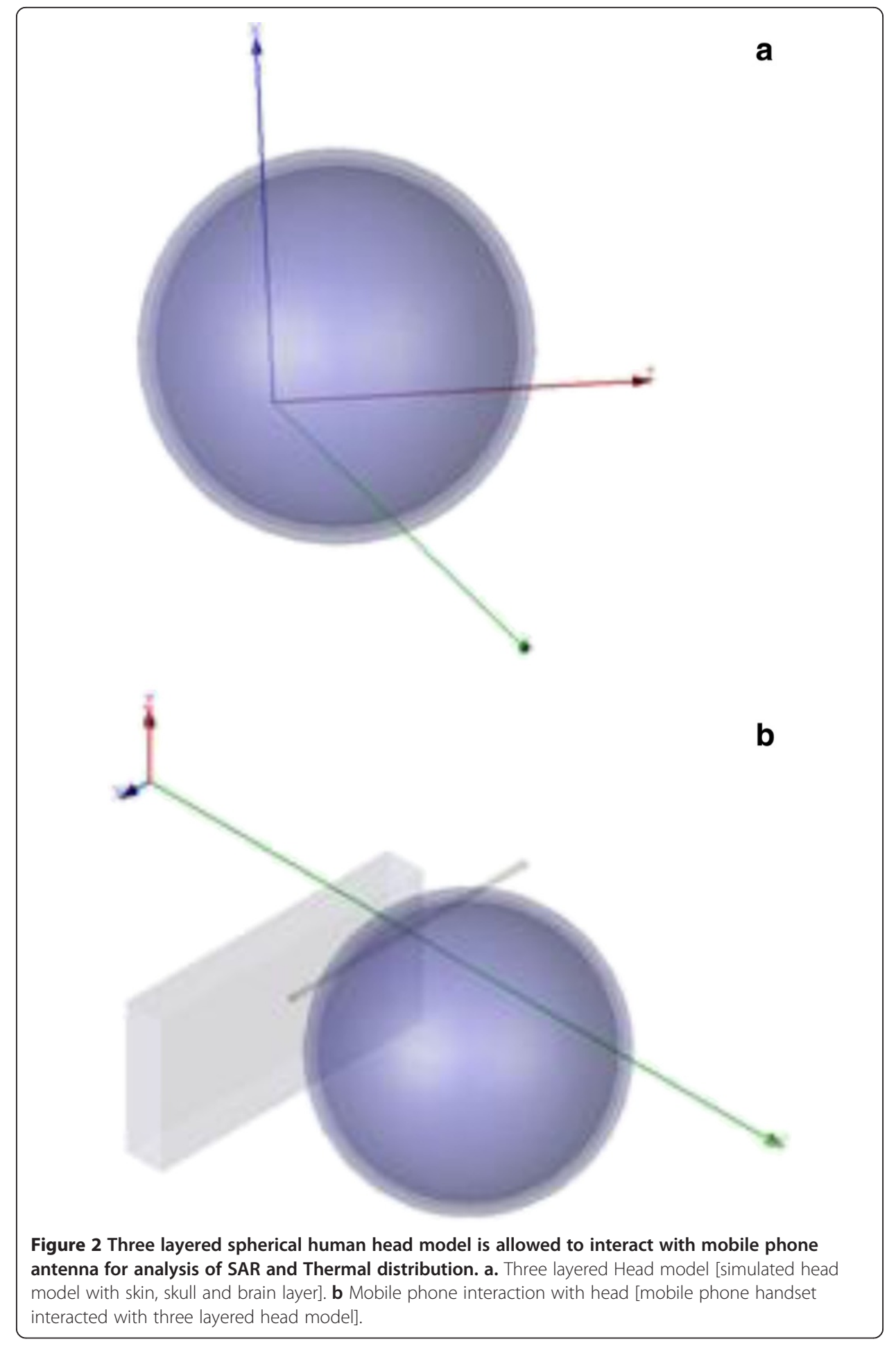


Table 1 Properties of tissues in human head

\begin{tabular}{llll}
\hline Tissue & Brain diameter $(\mathbf{m m})$ & Skull thickness $(\mathbf{m m})$ & Skin thickness $(\mathbf{m m})$ \\
\hline 4 year child & 136.1 & 3.1 & 3.6 \\
8 year child & 140.6 & 3.5 & 4 \\
Adult & 160.1 & 8.9 & 7.2 \\
Permittivity & 52.7 & 12.5 & 35.2 \\
Conductivity $(\mathrm{S} / \mathrm{m})$ & 0.94 & 0.14 & 0.60 \\
\hline
\end{tabular}

of each arm of dipole is $73.5 \mathrm{~mm}$ and radius is $1.8 \mathrm{~mm}$. The material of dipole arms are selected to be perfect electric conductor. The lumped port excitation with $50 \mathrm{ohm}$ internal resistance is located in the feed gap. Maximum working frequency of $3 \mathrm{GHz}$ is specified for excitation source. Antenna performance was analyzed in section Conclusion by considering the parameters such as, the current distribution in each arm of dipole antenna, S - parameter. Starting with these initial requirements, we optimized the design through simulations using commercial software package based on the FiniteDifference Time-Domain technique. For analyzing SAR and thermal distributions, the near field environment may include a human head and antenna enclosed by a plastic frame, which may influence on antenna performance.

\section{User head model}

The user's head ( 4 years child, 8 years child and an adult) was modeled as a sphere with three layers [5] such as skin, skull and brain as shown in Figure 2a, using GEMS [6].

Human body tissues have different values of dielectric properties that is, permittivity and conductivity and these properties are the functions of several variables such as frequency, geometry and size of tissue, and water contents [5]. Table 1 shows the model properties and dimensions used in used in simulation.

\section{Hand held device model}

A handheld device model (shown in Figure 1b) used for human interaction was modeled by GEMS. Figure 2b shows the interaction of handheld geometric model which has a maximum dimension of $167 \mathrm{~mm} \times 23 \mathrm{~mm} \times 83 \mathrm{~mm}$ with spherical human head. Components considered for simulation are feeding port (dipole antenna), plastic cover $(\varepsilon r=4.4)$ and plastic cover was modeled as dielectric materials [7].

\section{Measurement of power absorbed}

\section{Specific absorption rate}

Specific absorption rate [8] is defined as the rate at which RF power is absorbed per unit mass by any part of the body given by

$$
\begin{aligned}
\operatorname{SAR} & =\left(\sigma|\mathrm{E}|^{\wedge} 2\right) /(\rho) \\
\mathrm{SAR} & =\mathrm{C}(\mathrm{dT} / \mathrm{dt})
\end{aligned}
$$

Where, $E$ is the effective value of the electric field intensity $(\mathrm{V} / \mathrm{m}), \mathrm{dT} / \mathrm{dt}$ is the time derivative of the temperature $(\mathrm{K} / \mathrm{s}), \sigma$ is the electrical conductivity $(\mathrm{S} / \mathrm{m}), \rho$ is the mass density $(\mathrm{kg} / \mathrm{m} 3)$ and $\mathrm{c}$ is the specific heat $(\mathrm{J} / \mathrm{kg} \mathrm{K})$. The unit of SAR is $\mathrm{W} / \mathrm{kg}$. Due to evolution in wireless technologies, dosimetric evaluation of handheld device is highly 

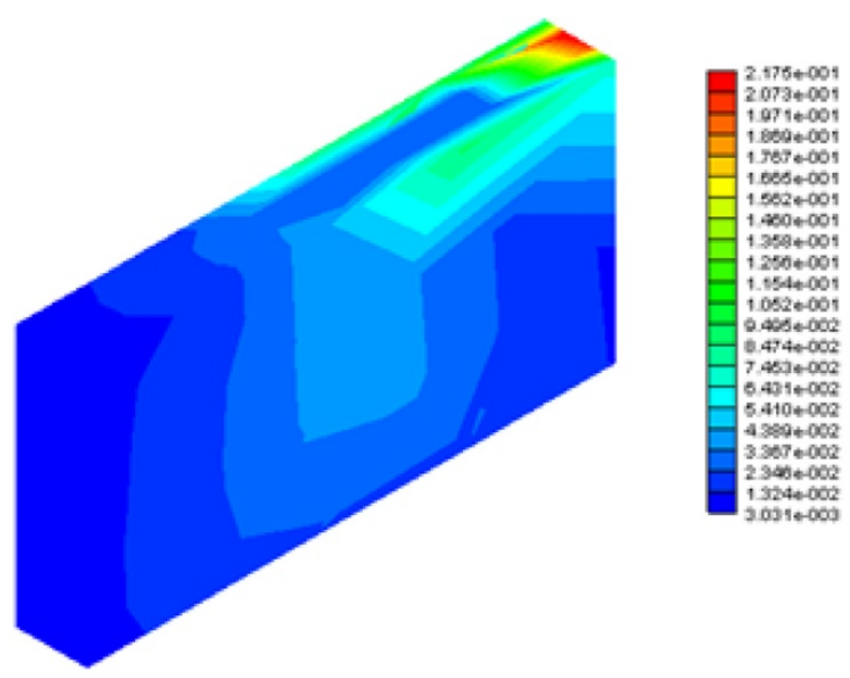

Figure 3 Current distribution in mobile phone [currrent is more near the antenna excitation feed shown by red colour in the simulation result].

desirable for safety environment [9]. For radio frequency signals, SAR value is calculated for either $1 \mathrm{~g}$ (Australia, United States) or $10 \mathrm{~g}$ (Europe, Japan) of simulated biological tissue in the shape of a cube. Partial (localized) non occupational exposure is limited to a spatial peak value not exceeding $1.6 \mathrm{~W} / \mathrm{kg}$ (Australia, United States) and $2.0 \mathrm{~W} / \mathrm{kg}$ (Japan). The partial exposure SAR limit recommended by the Council of the European Union and adopted by India is also $1.6 \mathrm{~W} / \mathrm{kg}[3]$.

Tissues are made up of water, different salts and organic compounds and they can be considered as a mixture of insulators and conductors. Brain tissue is rich in water along with fat content and cerebrospinal fluid along the ventricles and extends to flow along spinal cord. When a portable cellular telephone is in the typical use position, the nearest brain tissue is in matter of relatively uniform dielectric characteristics with macroscopic values of dielectric constant and conductivity $\varepsilon_{r}=52.7$ and $\sigma=0.94 \mathrm{~S} / \mathrm{m}$ in the frequency band of interest.

\section{Thermal effects}

Thermal effects are due to rise in temperature produced by the energy absorbed from oscillating electric fields emitted by mobile phone antennas as shown in Figure 3. The dark red colour shows higher temperature near antenna feeding point and get varies along the length of the case. Similarly, the current generated in brain tissue as in

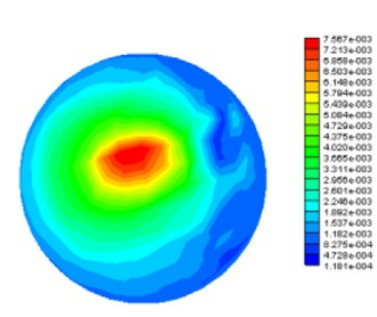

a

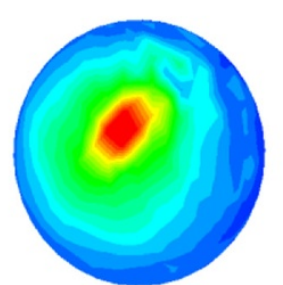

b

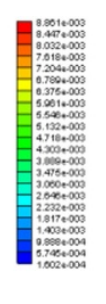

Figure 4 Current distribution in a) 4 year child, b) 8 year child, c) adult human head. 


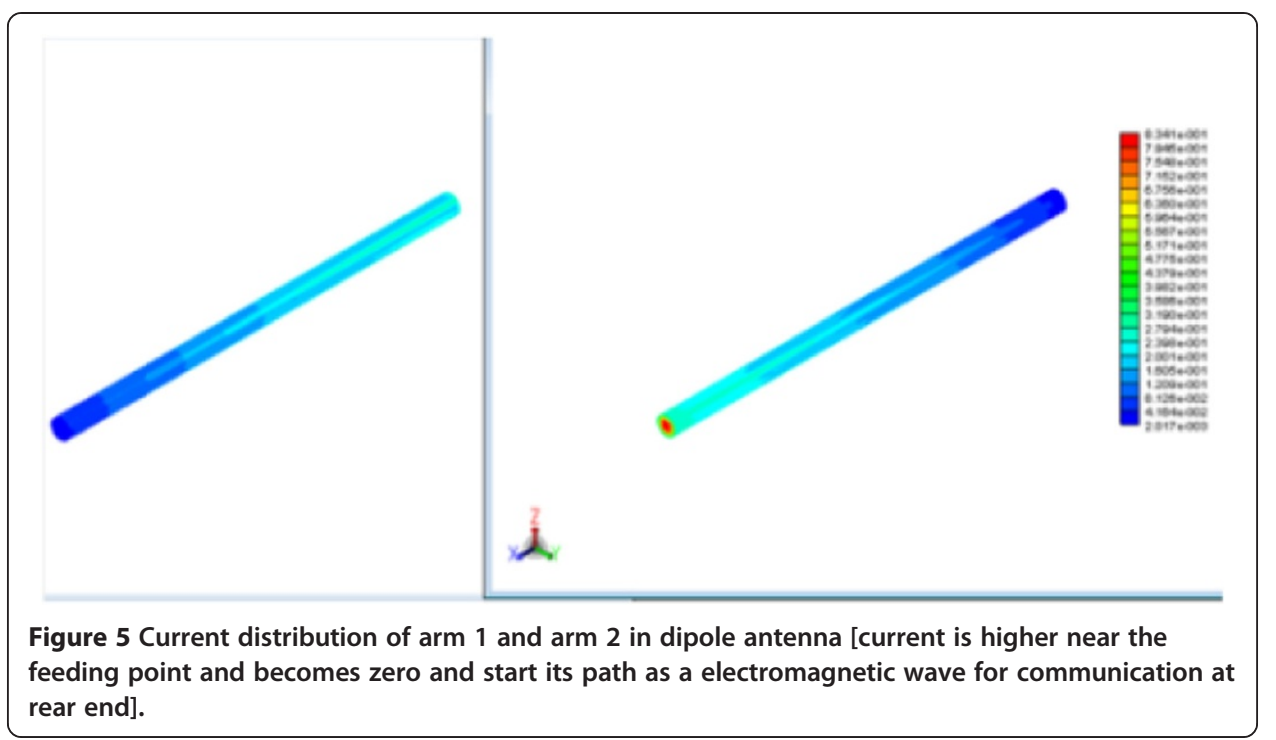

Figure 4 shows temperature variation. The power coupled causes the temperature to rise until, this induced heat reaches stable equilibrium value through blood circulation along the body which will take several minutes from the moment RF exposure occurs. Generally, thermal energy is dissipated from the body by sweating and increased peripheral circulation. The consequences of excessive heating in the body vary from temporary disturbances in cell functions to permanent destruction of tissues.

Studies [10] indicate that, the lens of eye may experience a temperature increase of $1^{\circ} \mathrm{C}$ at SAR level of $10 \mathrm{~W} / \mathrm{kg}$. At cell level the heating cause damage by disturbing the functioning of proteins. Cells begin to die when the temperature rises more than $5^{\circ} \mathrm{C}$, but the tissues can endure momentary increases of tens of degrees.

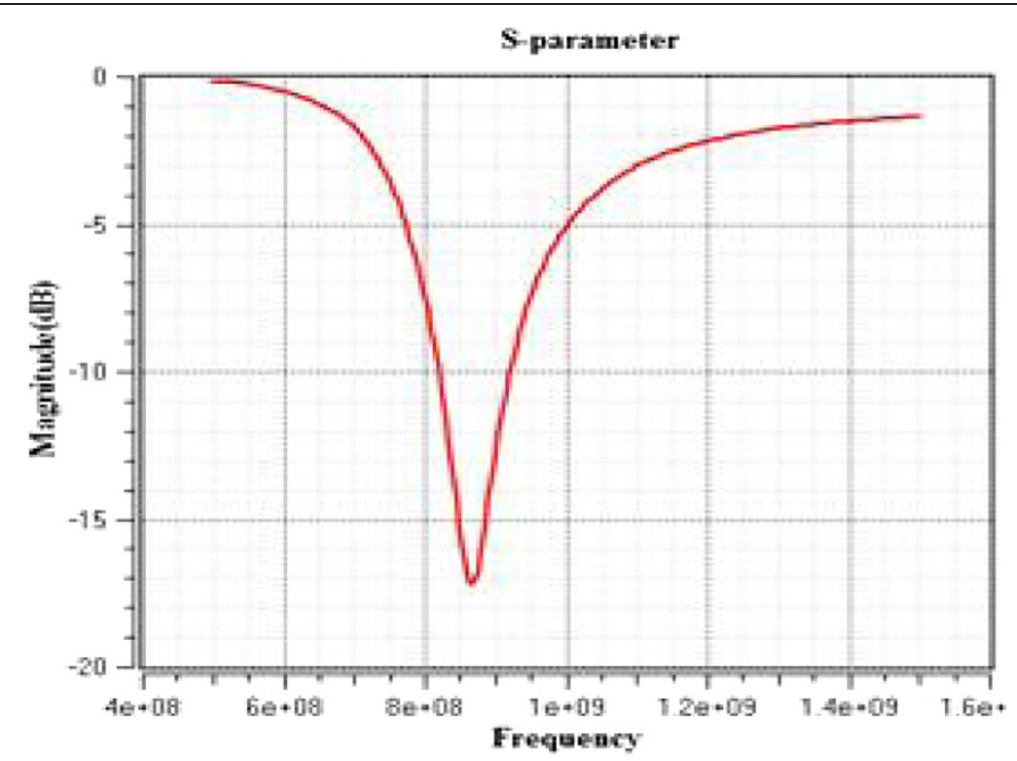

Figure 6 S-Parameters dipole antenna port [simulation results shows good return loss of more than $15 \mathrm{~dB}$, suitable for mobile communication]. 


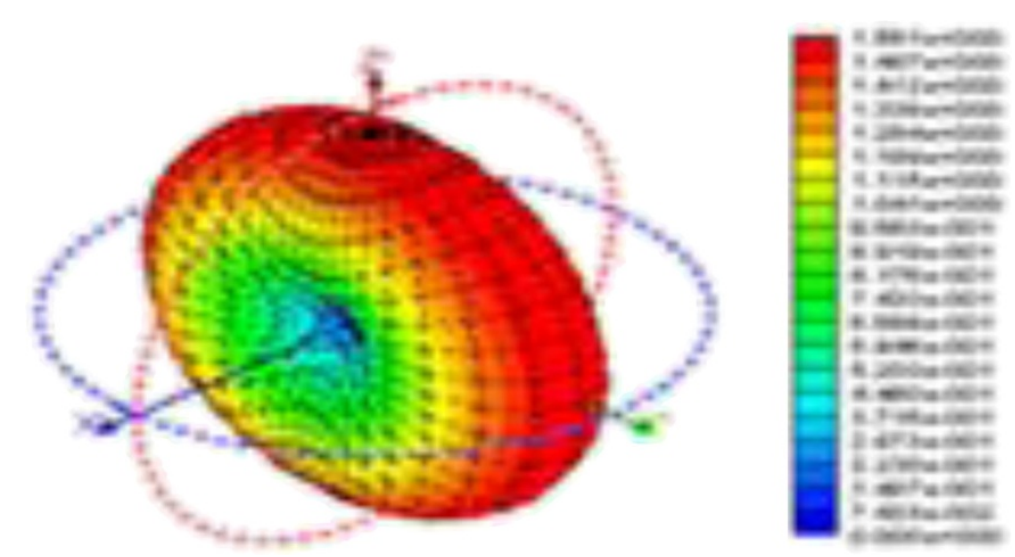

Figure 7 Radiation pattern of dipole antenna [simulated result of radiation pattern of dipole antenna].

\section{Numerical results and discussions}

\section{FDTD simulations}

Simulations using GEMS, a commercially available software package have been carried out in this paper. Finite Difference Time Domain is the popular computational technique, used for the computation of electromagnetic field and also its interaction with other materials. Here, computational space is divided into a Cartesian coordinate grid of voxels and then allocates the components of the electric and magnetic fields to specified locations on each voxel. This scheme is known as Yee lattice and the components are distributed in such a way that, every $\mathrm{H}$-field component is surrounded by E-field components and vice versa. In addition to discretizing $\mathrm{E}$ and $\mathrm{H}$ in the space, the temporal changes in the fields are computed at discrete time intervals. For spatial grid separations of $\Delta t$, the fields may be written as

$$
\mathrm{F}(\mathrm{x}, \mathrm{y}, \mathrm{z}, \mathrm{t})=\mathrm{F}(\mathrm{i} \Delta \mathrm{x}, \mathrm{j} \Delta \mathrm{y}, \mathrm{k} \Delta \mathrm{z}, \mathrm{n} \Delta \mathrm{t})
$$

From this the $\mathrm{x}, \mathrm{y}, \mathrm{z}$ component of electric and magnetic field values are calculated at each time by updating the values from the previous time step by the curl of the
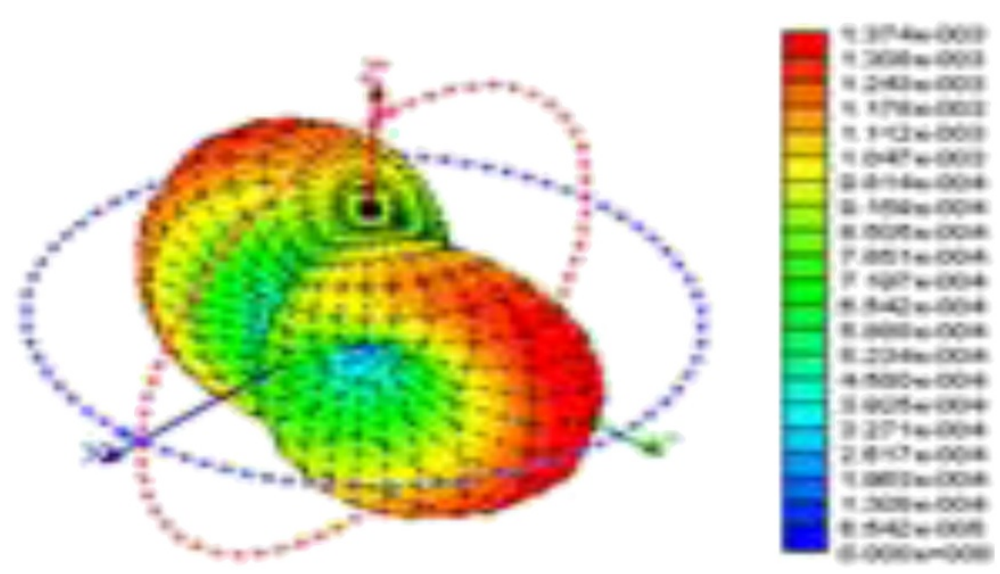

Figure 8 Radiation pattern of antenna due to human interaction. [altered radiation pattern from the original pattern due to human interaction]. 
Table 2 SAR averaged over $1 \mathrm{~g}$ and $10 \mathrm{~g}$ tissue when phone (without resistive sheet) placed near head

\begin{tabular}{llll}
\hline Model & 4-year child & 8-year child & Adult \\
\hline 1-g SAR $(\boldsymbol{W} / \mathbf{K g})$ & 20.47 & 14.27 & 4.27 \\
$\mathbf{1 0 - g}$ SAR $(\boldsymbol{W} / \mathbf{K g})$ & 8.13 & 6.92 & 2.78 \\
Max SAR $(\boldsymbol{W} / \mathbf{K g})$ & 149.9 & 73.10 & 11.15 \\
Average SAR $(\boldsymbol{W} / \mathbf{K g})$ & 0.52 & 0.48 & 0.168 \\
\hline
\end{tabular}

complementary field. The computational starting point is defined by the initial condition, achieved by applying a sinusoidal or impulsive propagating wave beginning at $n=$ 0 . At each increment of $n$, the solution for $E$ and $H$ evolve as wave propagates [3,11]. In this section, first the performance evaluation of antenna in free space is considered. Further, the interaction of six layered spherical human head with mobile phone is evaluated for measurement of SAR and heat induced.

\section{Evaluation of antenna in free space}

\section{Current distribution and S- parameters}

General Electro Magnetic Simulator was used to generate animations of the electric surface currents with feeding port excited. Current distribution along the arms of dipole antenna is shown in Figure 5. The excitation of the port induces high-magnitude surface currents in the proximity of each feed, but a null-current area is clearly shown to exist at the open circuit end. The simulated S-parameter of the $\lambda / 2$ dipole antenna is shown in Figure 6.

The results indicate that, for frequency band of interest $(0.9-1.5 \mathrm{GHz})$, feeding port provides a better return loss of $15 \mathrm{~dB}$, suitable for wireless communication applications $[12,13]$.

\section{Radiation pattern and efficiency}

Figure 7 illustrates the simulated 3-D gain patterns for $(\lambda / 2)$ dipole antenna, for the operating frequency of $0.9 \mathrm{GHz}$. The total efficiency of an antenna is defined as the ratio of total radiated power to the incident power at the feed. Forward efficiency of antenna in free space is found to be $95 \%$ at $0.9 \mathrm{GHz}$. From Figure 8, it is also seen that, the original radiation pattern of dipole antenna get altered due human head interaction [14].

\section{Mobile phone interaction with head model}

\section{SAR analysis}

The spherical human head composed of three inner layers (as in Table 1) is simulated and is allowed to interact with the mobile phone placed very near to ear (pressing the ear).

Table 3 SAR values averaged over tissues when phone with resistive sheet placed near user head model

\begin{tabular}{lllllll}
\hline Model & 4-year child & \% decrement & 8-year child & \% decrement & Adult & \% decrement \\
\hline 1-g SAR $(\boldsymbol{W} / \mathbf{K g})$ & 9.709 & 52.5 & 5.825 & 59.2 & 2.13 & 50.1 \\
10-g SAR $(\boldsymbol{W} / \mathbf{K g})$ & 4.43 & 45.5 & 3.24 & 53.1 & 1.35 & 51.4 \\
Max SAR (W/Kg) & 65.77 & 55.5 & 23.90 & 67.3 & 6.36 & 42.9 \\
Average SAR $(\boldsymbol{W} / \mathbf{K g})$ & 0.32 & 38.9 & 0.243 & 49.3 & 0.095 & 43.15 \\
\hline
\end{tabular}




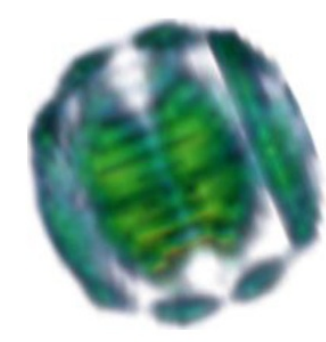

a

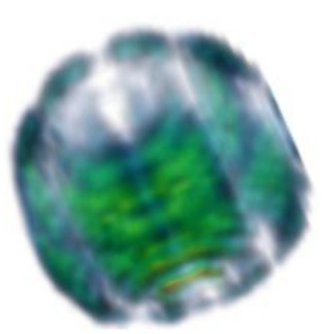

b

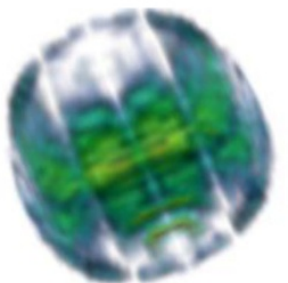

C

Figure 9 3D thermal distributions in a) 4 year child, b) 8 year child, c) Adult human head.

The values of maximum SAR, average SAR and SAR averaged over 1 and $10 \mathrm{~g}$ of human tissue have been computed, when mobile phone placed near human head and are listed in Tables 2 and 3. The power absorption level of each layer differs due to its thickness, conductivity and permittivity [15]. Current distribution and 3D thermal distribution in head is shown in Figures 4 and 9. From the results obtained (shown in Figures 10 and 11), the SAR values are higher for children.

In this work, application of resistive sheet of $50 \mathrm{ohm}$ is placed on the user front side of mobile phone handset case. And the comparative result shows, considerable decrement in power coupled. This introduced method shows maximum of $50 \%$ decrement in power coupled.

\section{Conclusion}

From the studies and above simulation results, it is concluded that, the power absorbed by children head is higher than adult. It might be due to variation in the head tissue layer thickness, which is lower in case of children. Since, the skull bone of adult is very thick comparatively; the intensity of power coupled to the brain is lesser. Further, the inclusion of $50 \mathrm{ohm}$ resistive sheet in handset decreases the power coupled with the human head.

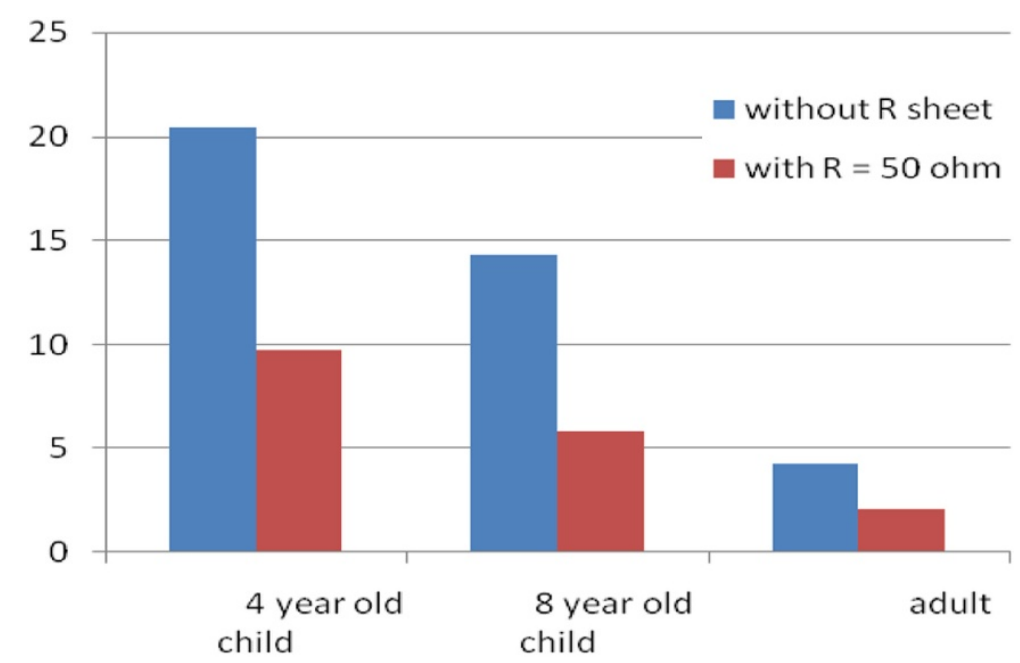

Figure 10 Graphical representations of $1 \mathrm{~g}$ - SAR values for children and adult [analysis shows that child head absorbs more radiation than adult]. 


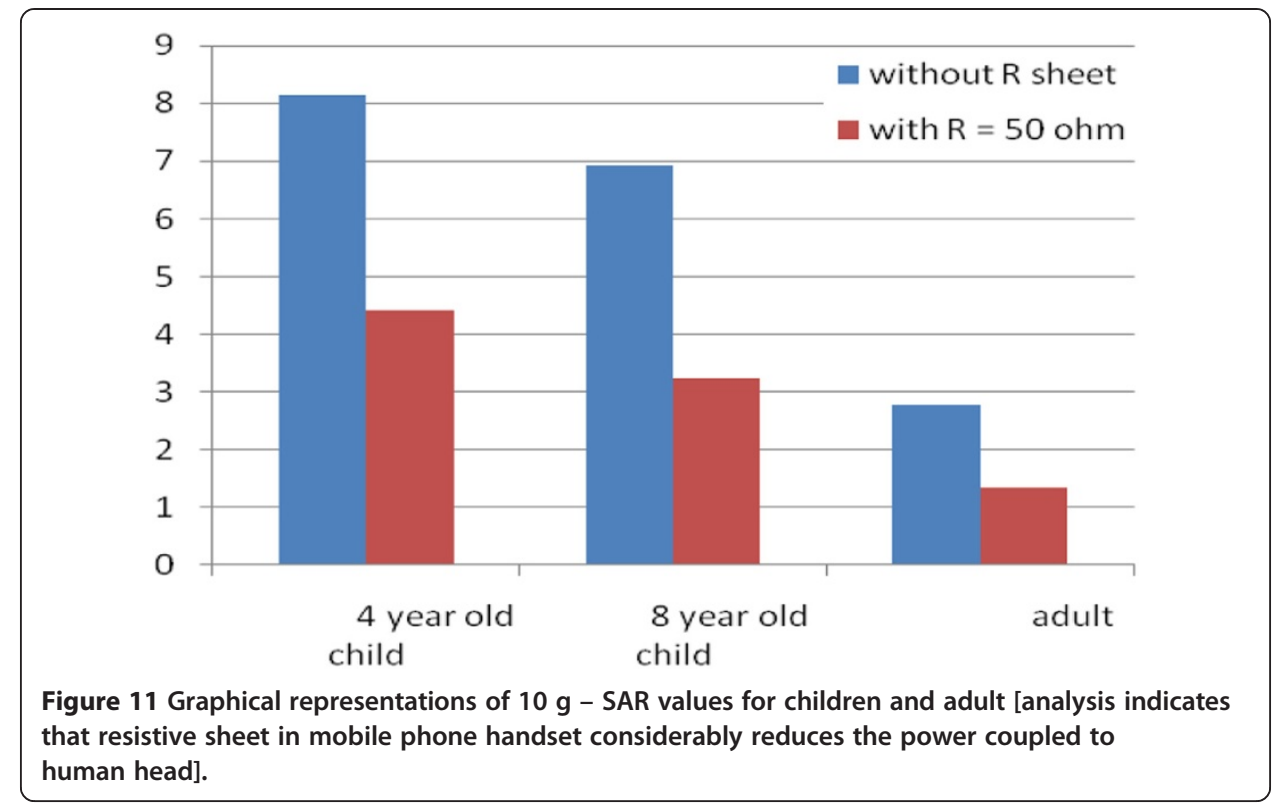

\section{Competing interests}

The authors declare that they have no competing interest.

\section{Authors' contributions}

BR has published papers in the area of intellectual property rights and had been member of various technical societies. In this work, BR contributed the whole research idea and extended his help through out the work like documentation to final verification. LR done simulation and documentation work. Both the author has read the final manuscript. Both authors read and approved the final manuscript.

\section{Authors' information}

Balamurugan Rajagopal was born in Tamil Nadu, India in 1981. He received the Bachelor's degree in EIE from NIT Jalandar, Punjab, India and Master's in Electrical Engineering from Anna University, TN, India. Since 2007, he is working as an Assistant Professor in Department of Electrical Engineering in Anna University Regional Centre, Coimbatore, TN, India. He's been granted for staff mobility program through Heritage program and India for you. His research interest includes Intellectual Property Rights, Power electronic converters for renewable energy systems, Bio-electromagnetics. Lalithambika Rajasekaran was born in Tamil Nadu, India in 1987. She received the Bachelor degree in Electronics and Communication Engineering and Master's in Electrical Engineering in 2009 and 2013 respectively from Anna University, Tamil Nadu, India. She was awarded with Gold medal in her Masters degree. Her research interest includes Bio- Electromagnetics, power electronic converters for renewable energy systems.

\section{Acknowledgment}

I wish to thank Doctors of various hospitals by giving their valuable explanations regarding Human anatomy and the difference between adult and child head.

Received: 19 March 2014 Accepted: 9 April 2014

Published online: 13 August 2014

\section{References}

1. Abdelhamid H, Emmanuelle C, Azeddine G, Man-Fa"I W, Joe W (2010) 'Analysis of power absorbed by children's head as a result of new usages of mobile phone'. IEEE Trans Electromagn Compat 52:4

2. Rowley JT, Waterhouse RB (1999) 'Performance of shorted microstrip patch antennas for mobile communications handsets at $1800 \mathrm{MHz}$. IEEE Trans Antennas Propag 47:5

3. Kraus JD, Fleich DA (1999) "Electromagnetics with applications', Fifthth edn. New York: Mc-Graw-Hill

4. Carr JJ (2001) 'Practical antenna handbook', Fourthth edn. New York: Mc Graw-Hill, ISBN-10: 0071374353

5. Anderson V (2003) 'Comparisons of peak SAR levels in concentric sphere head models of children and adults for irradiation by a dipole at $900 \mathrm{MHz}$ ' Institute of Physics Publishing Physics in Medicine and Biology. Phys Med Biol 48:3263-3327

6. Simulation tool, 'General Electromagnetic Simulator', http://www.2comu.com

7. Rao Q, Wang D (2010) 'A compact dual port diversity antenna for long-term evolution handheld devices'. IEEE Trans VehTech 59:59

8. Kivekas O, Ollikainen J, Lehtiniemi T, Vainikainen P (2004) 'Bandwidth, SAR and efficiency of internal mobile phone antennas.' IEEE Trans Electromagn Compat, 46(1):71-86 
9. Jensen MA, Rahmat-Samii Y (1994) 'Performance analysis of antennas for hand-held transceivers using FDTD'. IEEE Trans Antennas Propag 42(8):1106-1113

10. Environmental Working Group (2009) 'Cell Phone Radiation, Science Review on Cancer Risk and Children Health'. http://www.ewg.org/cellphoneradiation/fullreport

11. Bansal R (ed) (2004) 'Handbook of engineering electromagnetics'. Marcel Dekker, USA

12. Rao Q, Wilson K (2011) 'Design, modeling, and evaluation of a multiband MIMO/Diversity Antenna System for small wireless mobile terminals'. IEEE Trans Comp Packag Manufact Technol 01:03

13. Vaughan RG, Anderson JB (1987) 'Antenna diversity in mobile communications'. IEEE Trans Veh Technol Vt-36 (4):149-172

14. Tang CK, Fung LC, Leung SW (2007) 'Electromagnetic field radiation of mobile phone inside metallic enclosure'. IEEE International Symposium on Electromagnetic Compatibility, 2007 1-6

15. Ilvonen S, Sarvas J (2007) 'Magnetic-field-induced elf currents in a human body by the use of a GSM phone'. IEEE Trans Electromagn Compat 49:2

doi:10.1186/s13673-014-0010-1

Cite this article as: Rajagopal and Rajasekaran: SAR assessment on three layered spherical human head model irradiated by mobile phone antenna. Human-centric Computing and Information Sciences 2014 4:10.

Submit your manuscript to a SpringerOpen ${ }^{\odot}$ journal and benefit from:

- Convenient online submission

- Rigorous peer review

- Immediate publication on acceptance

- Open access: articles freely available online

- High visibility within the field

Retaining the copyright to your article

Submit your next manuscript at $\boldsymbol{\sim}$ springeropen.com 